\title{
Response of spring barley varieties to the protection level in two systems of crop sequence
}

\author{
Reakcja odmian jęczmienia jarego na poziom ochrony \\ w dwóch systemach następstwa roślin
}

\author{
Ewa Adamiak*, Jan Adamiak, Dagmara Szałczyńska
}

\section{Summary}

In 3-year research (2011-2013) carried out in static field experiment on luvisol medium soil in Production and Experimental Plant Bałcyny near Ostróda town, the response of two varieties of spring barley (Conchita and Mercada) to a chemical protection against weeds $(\mathrm{H})$, and combined protection from weeds and diseases (HF) was evaluated. The comparisons of responses were carried out in two following crop sequence systems: A) the cultivation of spring barley varieties in 6-field crop rotation: sugar beet - maize - spring barley - pea - winter rape - winter wheat and B) the cultivation in 45-47-year monoculture. The cultivation of barley without any protection (O) in both crop sequence systems was a control object. The research showed that the crop sequence system significantly differentiated the response of varieties to applied levels of a protection. Significantly higher increase of grain yield of spring barley varieties as a result of herbicides application as well as combined application of herbicides and fungicides was reported in the monoculture than in the crop rotation. In the both crop sequence systems the applied protection levels caused higher increase of yields for Mercada variety. In its case a significantly higher yield of grain was also achieved.

Key words: spring barley; varieties; crop rotation; monoculture; protection level

\section{Streszczenie}

W 3-letnich badaniach (2011-2013) prowadzonych w statycznym doświadczeniu polowym na glebie płowej, średniej, w Zakładzie Produkcyjno-Doświadczalnym Bałcyny koło Ostródy oceniono reakcję dwóch odmian jęczmienia jarego (Conchita, Mercada) na chemiczną ochronę przed chwastami $(\mathrm{H})$ oraz łącznie na ochronę przed chwastami i chorobami (HF). Porównania reakcji dokonano w dwóch systemach następstwa roślin: A) uprawa odmian jęczmienia jarego w 6-polowym płodozmianie: burak cukrowy - kukurydza jęczmień jary - groch siewny - rzepak ozimy - pszenica ozima i B) uprawa w 45-47-letniej monokulturze. Obiektem kontrolnym w obu systemach następstwa roślin była uprawa odmian jęczmienia bez żadnej ochrony (0). Badania wykazały, że system następstwa roślin istotnie różnicował reakcję odmian na stosowane poziomy ochrony łanu. Istotnie większe zwyżki plonów ziarna odmian jęczmienia jarego w wyniku stosowania herbicydów oraz łącznie herbicydów i fungicydów uzyskano w monokulturze niż w płodozmianie. W obu systemach następstwa roślin na stosowane poziomy ochrony korzystniej wzrostem plonów reagowała odmiana Mercada. W jej przypadku uzyskano także istotnie większy plon ziarna.

Słowa kluczowe: jęczmień jary; odmiany; płodozmian; monokultura; poziom ochrony

*corresponding author: ewa.adamiak@uwm.edu.pl 


\section{Wstęp / Introduction}

Jęczmień jary należy do zbóż o małej konkurencyjności wobec chwastów. Zalicza się także do gatunków o dużej wrażliwości na choroby. Uzyskanie wysokich plonów wymaga stosowania chemicznej ochrony łanu. Piśmiennictwo naukowe z zakresu reakcji jęczmienia jarego na chemiczne odchwaszczanie podaje, że zastosowanie herbicydów podnosi plonowanie jęczmienia jarego $\mathrm{w}$ zakresie od 1 do 21\% (Boatman 1992; Noworolnik 2010; Urban i Grządka 2012; Miklaszewska i Kierzek 2013). Z kolei plonochronne działanie fungicydów potwierdzone jest 0-29\% wzrostem plonów ziarna jęczmienia jarego (Boatman 1992; Yang i wsp. 2000; Noworolnik 2012). Stosunkowo ubogo jest natomiast przedstawiona reakcja jęczmienia jarego na chemiczną ochronę łanu w zależności od systemu następstwa roślin (Zawiślak i Adamiak 1998; Adamiak i Adamiak 1999; Adamiak i wsp. 2000). Celem niniejszej pracy było przybliżenie tego tematu.

Biorąc pod uwagę powyższe fakty, w przyjętej hipotezie badawczej założono, że długotrwała uprawa jęczmienia jarego w różnych systemach następstwa roślin może różnicować jego reakcję na poziom chemicznej ochrony. Jej weryfikacji dokonano realizując badania w wieloletnim doświadczeniu polowym, których celem była ocena plonowania dwóch odmian jęczmienia jarego chronionych chemicznie przed chwastami oraz chwastami i chorobami, uprawianych w 6-polowym płodozmianie i długotrwałej monokulturze.

\section{Materiały i metody / Materials and methods}

Praca przedstawia 3-letnie wyniki badań prowadzonych w latach 2011-2013 w Zakładzie Produkcyjno-Doświadczalnym w Bałcynach koło Ostródy, w statycznym doświadczeniu polowym, na glebie płowej, średniej, wytworzonej z gliny lekkiej, zalegającej na piasku gliniastym. Pod względem rolniczej przydatności glebę zaszeregowano do klas bonitacyjnych IIIa i IIIb, kompleksu pszennego dobrego. Schemat badań uwzględniał następujące czynniki:

I. System następstwa roślin: A) uprawa jęczmienia jarego w 6-polowym płodozmianie: burak cukrowy kukurydza - jęczmień jary - groch siewny - rzepak ozimy - pszenica ozima; B) uprawa jęczmienia jarego w 45-47-letniej monokulturze.

II. Poziom chemicznej ochrony łanu: $\mathrm{O}$ - bez ochrony; $\mathrm{H}$ - ochrona przed chwastami; HF - ochrona przed chwastami i chorobami.

III. Odmiany jęczmienia jarego: a) Conchita, b) Mercada.

Odmiany jęczmienia jarego wysiewano w ilości $3 \mathrm{mln}$ kiełkujących ziaren na 1 ha między 27 marca a 14 kwietnia. Nawożenie mineralne, identyczne w obu systemach następstwa roślin, wyniosło $184 \mathrm{~kg} \mathrm{NPK}$ na 1 ha $(\mathrm{N}-70$; $\mathrm{P}-31 ; \mathrm{K}-83)$. Dodatkowo co 3 lata monokultura jęczmienia jarego nawożona była obornikiem w ilości $15 \mathrm{t} / \mathrm{ha}$ celem zrównoważenia nawożenia naturalnego stosowanego w płodozmianie pod burak cukrowy (30 t/ha).

Chwasty zwalczano herbicydem Mustang 306 SE (s.cz.: florasulam + 2,4 D) w latach 2011 i 2012 oraz mieszaniną Chwastox Turbo 340 SL (s.cz:: MCPA + dikamba) + Puma Uniwersal 069 EW (s.cz.: fenoksapropP-etylowy) - w 2013 roku w fazie rozwojowej jęczmienia BBCH 16-22. Choroby grzybowe zwalczano stosując 2-krotne opryskiwanie $\mathrm{w}$ okresie wegetacji jęczmienia jarego następującymi fungicydami: Amistar $250 \mathrm{SC}$ (s.cz.: azoksystrobina); Amistar $250 \mathrm{SC}+$ Artea 330 EC (s.cz.: propikonazol + cyprokonazol); Capalo 337,5 (s.cz.: fenpropimorf + metrafenon + epoksykonazol); Fandango 200 EC (s.cz.: protiokonazol + fluoksastrobina).

\section{Wyniki i dyskusja / Results and discussion}

Badane odmiany jęczmienia jarego różniły się reakcją na poziom ochrony $\mathrm{w}$ poszczególnych systemach następstwa roślin. W płodozmianie na obiekcie bez żadnej ochrony istotnie wyżej plonowała odmiana Conchita, natomiast w niechronionej monokulturze istotnie większym plonem ziarna charakteryzowała się odmiana Mercada (tab. 1). Tak kształtujące się plonowanie odmian na tym obiekcie ochrony jest skorelowane $\mathrm{z}$ zachwaszczeniem ich łanów w fazie kwitnienia. W płodozmianie obsada chwastów, licząca $235 \mathrm{szt} . / \mathrm{m}^{2}$, w łanie odmiany Conchita była o 12\% mniejsza, podczas gdy w monokulturze $\left(383 \mathrm{szt} . / \mathrm{m}^{2}\right)$ o $14 \%$ większa niż w łanie odmiany Mercada. Zastosowanie chemicznej ochrony przed chwastami istotnie zwiększyło plonowanie jęczmienia jarego, zarówno w płodozmianie (o 6,3\%), a przede wszystkim w monokulturze (o 29,8\%). Bliższa analiza pokazuje, że w płodozmianie istotnym wzrostem plonu wykazała się jedynie odmiana Mercada. U odmiany Conchita zarysowała się minimalna tendencja spadkowa. W monokulturze zastosowanie tego wariantu ochrony istotnie podniosło wydajność ziarna obu odmian jęczmienia jarego. Większym wzrostem plonu, o 1,55 t/ha (o 33,1\%) charakteryzowała się odmiana Mercada. Odmiana Conchita podniosła swoją wydajność o $1,19 \mathrm{t} / \mathrm{ha}$ (o 26,3\%). O pozytywnym, istotnym wpływie działania herbicydów na plonowanie jęczmienia jarego informuje wielu autorów. Boatman (1992) po zastosowaniu herbicydów uzyskał wzrost plonów ziarna jęczmienia jarego w zakresie 0,05-1,21 t/ha. Noworolnik (2010) donosi, że herbicydy podniosły plonowanie jęczmienia jarego o 6-12\% w zależności od użytego środka i odmiany. Największą zwyżką plonów wykazała się odmiana Granal. W badaniach Urbana i Grządki (2012) herbicydy istotnie zwiększyły produkcyjność jęczmienia jarego, a większe przyrosty plonów, rzędu 7,5-14,2\%, uzyskano w uprawie odmiany Mauritia niż Stratus (6,5-11,1\%). Z kolei w badaniach Miklaszewskiej i Kierzka (2013), w zależności od dawki zastosowanych herbicydów, wzrost plonów jęczmienia jarego wahał się od 3,1 do 7,8\%. We wcześniejszych badaniach, wykonanych w tym doświadczeniu w latach 1983-1987 przez Zawiślak i Adamiak (1998) herbicydy zwiększyły wydajność jęczmienia jarego o 2,1\% w płodozmianie i o 4,3\% w monokulturze. W późniejszych o 10 lat badaniach, Adamiak i Adamiak (1999) uzyskali 5,3\% spadek plonu jęczmienia w płodozmianie i zerowy wzrost w monokulturze. 
Tabela 1. Plony ziarna jęczmienia jarego [t/ha], średnie z lat 2011-2013

Table 1. Yields of spring barley grain [t/ha], mean for 2011-2013

\begin{tabular}{|c|c|c|c|}
\hline \multirow{2}{*}{$\begin{array}{l}\text { Poziom ochrony } \\
\text { Protection levels }\end{array}$} & \multirow{2}{*}{$\begin{array}{l}\text { Odmiany } \\
\text { Varieties }\end{array}$} & \multicolumn{2}{|c|}{$\begin{array}{l}\text { System następstwa roślin } \\
\text { Crop sequence system }\end{array}$} \\
\hline & & $\begin{array}{l}\text { płodozmian } \\
\text { crop rotation }\end{array}$ & $\begin{array}{l}\text { monokultura } \\
\text { monoculture }\end{array}$ \\
\hline \multirow{2}{*}{$\begin{array}{l}\text { Bez ochrony }(\mathrm{O}) \\
\text { Without protection }\end{array}$} & $\begin{array}{l}\text { Conchita } \\
\text { Mercada }\end{array}$ & $\begin{array}{l}6,67 \\
5,98\end{array}$ & $\begin{array}{l}4,52 \\
4,68\end{array}$ \\
\hline & średnio - mean & 6,33 & 4,60 \\
\hline \multirow{2}{*}{$\begin{array}{l}\text { Ochrona przed chwastami }(\mathrm{H}) \\
\text { Protection from weeds }\end{array}$} & $\begin{array}{l}\text { Conchita } \\
\text { Mercada }\end{array}$ & $\begin{array}{l}6,61 \\
6,85\end{array}$ & $\begin{array}{l}5,71 \\
6,23\end{array}$ \\
\hline & średnio - mean & 6,73 & 5,97 \\
\hline \multirow{2}{*}{$\begin{array}{l}\text { Ochrona przed chwastami i chorobami (HF) } \\
\text { Protection from weeds and diseases }\end{array}$} & $\begin{array}{l}\text { Conchita } \\
\text { Mercada }\end{array}$ & $\begin{array}{l}6,98 \\
7,21\end{array}$ & $\begin{array}{l}5,94 \\
6,74\end{array}$ \\
\hline & średnio - mean & 7,10 & 6,34 \\
\hline \multicolumn{2}{|l|}{$\begin{array}{l}\text { Średnio dla systemu następstwa roślin } \\
\text { Mean for crop sequence system }\end{array}$} & 6,72 & 5,64 \\
\hline \multicolumn{2}{|l|}{$\begin{array}{l}\text { Średnio dla poziomu ochrony } \\
\text { Mean for protection levels }\end{array}$} & \multicolumn{2}{|l|}{$\mathrm{O}-5,46$} \\
\hline
\end{tabular}

NIR $(0,05)$ dla: systemu następstwa roślin (1) - 0,32 t/ha; poziomów ochrony (2) - 0,18 t/ha; odmian (3) - 0,10 t/ha;

interakcji $1 \times 2-0,12 \mathrm{t} / \mathrm{ha}$; interakcji $1 \times 3-0,12 \mathrm{t} / \mathrm{ha}$; interakcji $2 \times 3-0,14 \mathrm{t} / \mathrm{ha}$; interakcji $1 \times 2 \times 3-0,20 \mathrm{t} / \mathrm{ha}$

$\operatorname{LSD}(0.05)$ for: crop sequence system (1) $-0.32 \mathrm{t} / \mathrm{ha}$; protection levels (2) $-0.18 \mathrm{t} / \mathrm{ha}$; varieties (3) $-0.10 \mathrm{t} / \mathrm{ha}$;

interaction $1 \times 2-0.12 \mathrm{t} / \mathrm{ha}$; interaction $1 \times 3-0.12 \mathrm{t} / \mathrm{ha}$; interaction $2 \times 3-0.14 \mathrm{t} / \mathrm{ha}$; interaction $1 \times 2 \times 3-0.20 \mathrm{t} / \mathrm{ha}$

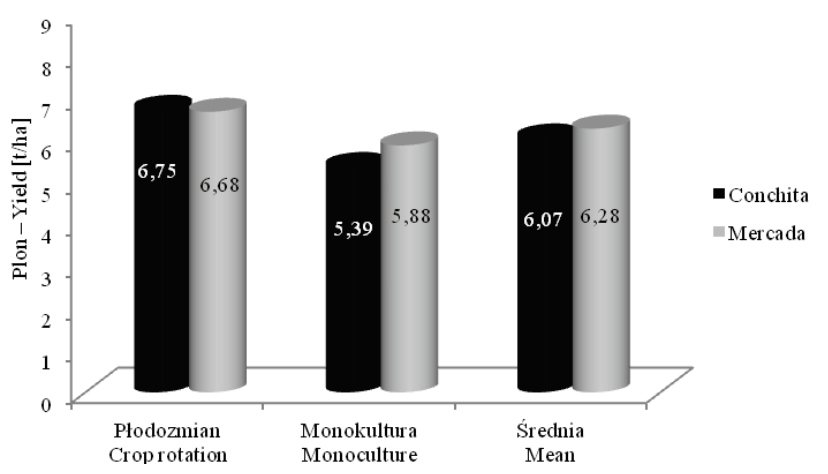

NIR $(0,05)$ dla: odmian $-0,10$ t/ha; systemu następstwa roślin $\mathrm{x}$ odmiana $-0,12$ t/ha

LSD (0.05) for: varieties $-0.10 \mathrm{t} / \mathrm{ha}$; crop sequence system $\mathrm{x}$ variety $-0.12 \mathrm{t} / \mathrm{ha}$

Rys. 1. Plonowanie odmian jęczmienia jarego w systemach następstwa roślin

Fig. 1. Yields of spring barley varieties in crop sequence systems

Uintensywnienie ochrony poprzez dodatkowe zastosowanie fungicydów, w porównaniu do obiektu traktowanego herbicydami, podniosło istotnie plony ziarna jęczmienia jarego w obu stanowiskach uprawy, w płodozmianie o $0,37 \mathrm{t} / \mathrm{ha}$ (o 5,5\%) i w monokulturze także o $0,37 \mathrm{t} /$ ha (o 6,2\%). W płodozmianie obie odmiany wykazały się podobnym przyrostem plonu ziarna, odmiana Conchita o $5,6 \%$, a Mercada o $5,3 \%$. W monokulturze dużo większą zwyżką wydajności charakteryzowała się odmiana Mercada (+8,2\%) niż Conchita $(+4,0 \%)$. O większej roli fungicydów w kształtowaniu plonu jęczmienia jarego w monokulturze niż $\mathrm{w}$ płodozmianie informowali wcześniej Zawiślak i Adamiak (1998), Adamiak i Adamiak (1999) oraz Adamiak i wsp. (2000), przy czym w badaniach tych pierwszych autorów korzystniej na aplikację fungicydów reagowała odmiana Diva niż Menuet, a w badaniach drugich autorów odmiana Nagrad niż Klimek. W badaniach Noworolnika (2012) zastosowanie fungicydów w większej skali podniosło plony odmiany Conchita niż pozostałych dwóch odmian - Mauritia i Sebastian, a zwyżki wynosiły 3,4-10,0\%. Boatman (1992) w wyniku aplikacji fungicydów w 3 doświadczeniach uzyskał wzrost wydajności jęczmienia jarego rzędu 9,3-11,8\%, a w kolejnych trzech eksperymentach zaledwie 0,2-6,3\%. Według Yanga i wsp. (2000) plonochronny efekt fungicydów zależy od zwalczanych patogenów. Informują oni, że największy wzrost plonów, dochodzący do $30 \%$, daje 2 -krotne opryskiwanie fungicydami, pierwsze na choroby liści, a drugie na choroby kłosa.

W sumie obie porównywane odmiany jęczmienia jarego, uwzględniając średnie dla poziomów ochrony łanu, wydały w badanym 3-leciu zbliżone plony ziarna w płodozmianie (rys. 1). W wieloletniej monokulturze istotnie wyżej plonowała odmiana Mercada. Charakteryzowała się także większym plonem ziarna. Również w mniejszym stopniu zareagowała na wieloletni siew po sobie, obniżając wydajność o $12 \%$, podczas gdy odmiana Conchita o $20 \%$.

\section{Wnioski / Conclusions}

1. Wykazano, że system następstwa roślin istotnie różnicował reakcję odmian jęczmienia jarego na poziom chemicznej ochrony łanu. W wyniku aplikacji herbicydów i fungicydów większe przyrosty plonów uzyskano w monokulturze niż w płodozmianie.

2. Na chemiczne zwalczanie chwastów w płodozmianie istotnym wzrostem wydajności ziarna reagowała jedynie odmiana Mercada, natomiast w monokulturze obie 
odmiany istotnie podniosły plony, przy czym większym wzrostem wykazała się odmiana Mercada.

3. Fungicydy w podobnym stopniu przyczyniły się do zwyżki plonów obu odmian w płodozmianie, natomiast w wieloletniej monokulturze bardziej zwiększyły plony ziarna odmiany Mercada.
4. Odmiana Mercada niezależnie od systemu następstwa roślin i wariantu ochrony, wykazała się istotnie większą produkcyjnością. Ona także w mniejszej skali zareagowała na uprawę w 45-47-letniej monokulturze spadkiem plonu ziarna.

\section{Literatura / References}

Adamiak E., Adamiak J. 1999. Reaktion der Sommergerste auf langjährige Monokultur. Mitteilungen der Gesellschaft für Pflanzenbauwissenschaften 12: 261-262.

Adamiak J., Adamiak E., Stępień A., Urbański B. 2000. Response of spring barley cultivars to higher cereal proportion in crop rotations and to monoculture. Natural Science 5: 35-43.

Boatman N.D. 1992. Effects of herbicide use, fungicide use and position in the field on the field and field components of spring barley. Journal of Agricultural Science 118: 17-28.

Miklaszewska K., Kierzek R. 2013. Skuteczność chwastobójcza obniżonych dawek preparatów Dragon 450 WG i Granstar Ultra SX 50 SG w uprawie jęczmienia jarego. [Response of weeds to different doses of Dragon 450 WG and Granstar Ultra SX 50 SG]. Progress in Plant Protection/Postępy w Ochronie Roślin 53 (1): 91-95.

Noworolnik K. 2010. Wpływ wybranych herbicydów na plonowanie i zachwaszczenie odmian jęczmienia jarego. [Effect of some herbicides on yielding and weed infestation of spring barley cultivars]. Progress in Plant Protection/Postępy w Ochronie Roślin 50 (1): 313-316.

Noworolnik K. 2012. Wpływ fungicydów na plonowanie i jakość ziarna browarnych odmian jęczmienia. [Effect of fungicides on yielding and grain quality of malting barley cultivars]. Progress in Plant Protection/Postępy w Ochronie Roślin 52 (3): $642-645$.

Urban M., Grządka M. 2012. Oddziaływanie zróżnicowanych dawek herbicydów na wysokość i strukturę plonów odmian jęczmienia jarego. [The influence of herbicide dose differentiation on the yield height and structure of yield spring barley cultivars]. Progress in Plant Protection/Postępy w Ochronie Roślin 52 (4): 927-931.

Yang J.P., Sieling K., Hanus H. 2000. Effects of Fungicide on Grain Yield of Barley Grown in Different Cropping Systems. Journal of Agronomy \& Crop Science 185: 153-162.

Zawiślak K., Adamiak E. 1998. Płodozmian i pestycydy jako czynniki integrowanej uprawy jęczmienia jarego. Acta Academiae Agriculturae ac Technicae Olstenensis, Agricultura 66: 119-129. 